\title{
Revisitando a flora de Macaé de Cima, Rio de Janeiro, Brasil: o gênero Psidium (Myrtaceae)
}

Revisiting the flora of Macaé de Cima, Rio de Janeiro, Brazil: the genus Psidium (Myrtaceae)

\author{
Amélia C. Tuler ${ }^{1,3}$, Tatiana T. Carrijo ${ }^{2}$ \& Ariane L. Peixoto ${ }^{1}$
}

\begin{abstract}
Resumo
As espécies de Psidium de Macaé de Cima, Rio de Janeiro, Brasil foram revisitadas após pouco mais de 20 anos da publicação do estudo de Myrtaceae para este trecho de Floresta Atlântica, a qual atualmente se constitui em uma Área de Proteção Ambiental. A identificação das espécies foi realizada com base em análise de coleções depositadas em herbário e observação dos indivíduos a campo. Os resultados incluem o tratamento taxonômico, chave de identificação, comentários e registro fotográfico das espécies. O número de espécies de Psidium na área de estudo foi ampliado de três para seis espécies, uma das quais $P$. ovale representando uma nova ocorrência para o estado do Rio de Janeiro. Os resultados revelaram a necessidade de estudos continuados de flora, especialmente em áreas de alta diversidade, e a sua importância para conservação das espécies e gestão de áreas protegidas.

Palavras-chave: conservação, flora do Brasil, Floresta Atlântica, riqueza de espécies, taxonomia.
\end{abstract}

\begin{abstract}
Psidium species of Macaé de Cima, Rio de Janeiro, Brazil were revisited after just over 20 years since the publication of the Myrtaceae study for this area of Atlantic forest, which currently constitutes an Environmental Protection Area. The species identification was based on analysis of herbarium collections, and observation of individuals in the field. The results include the taxonomic treatment, identification key, comments and photographic record of the species. The number of species of Psidium in the study area was expanded to three for six species, one of which $P$. ovale represents a new record for the state of Rio de Janeiro. The results showed the need for continued studies of flora, especially in high-diversity areas, and its importance for conservation of species and protected areas management.
\end{abstract}

Key words: conservation, Brazilian flora, Atlantic Forest, species richness, taxonomy.

\section{Introdução}

A Floresta Atlântica é um complexo de ecossistemas que abriga 15.001 espécies de Angiospermas, das quais $7.432(49,5 \%)$ são endêmicas desse domínio fitogeográfico (BFG 2015). É considerada uma área prioritária para conservação, dado que apresenta apenas $11,7 \%$ de sua extensão original, sendo apenas $1,62 \%$ legalmente protegidos (Ribeiro et al. 2009). Os altos níveis de riqueza e endemismo, associados à destruição sofrida no passado, incluíram a Floresta Atlântica definitivamente no cenário mundial como um dos 34 hotspots de biodiversidade (Mittermeier et al. 2004).
Essa imensa riqueza de espécies e a diversidade de paisagens instiga naturalistas e botânicos desde o século XIX a estudar os diversos grupos presentes na Mata Atlântica, bem como seus ambientes de ocorrência. Dentre as inúmeras iniciativas para estudos de trechos da Floresta Atlântica ressalta-se aqui estudos multidisciplinares realizados por equipes do Instituto de Pesquisas Jardim Botânico do Rio de Janeiro (JBRJ), na então Reserva Ecológica de Macaé de Cima (REMC), iniciados em 1988. A REMC hoje integra a Área de Proteção Ambiental (APA) Estadual de Macaé de Cima, cuja área física foi ampliada para salvaguardar outros trechos

'Escola Nacional de Botânica Tropical, Instituto de Pesquisas Jardim Botânico do Rio de Janeiro, R. Pacheco Leão 2040, 22460-030, Rio de Janeiro, RJ, Brasil. ${ }^{2}$ Universidade Federal do Espírito Santo, Centro de Ciências Agrárias, Depto. Biologia, 29500-000, Guararema, Alegre, ES, Brasil. 
igualmente importantes da Floresta Atlântica (Sá Rego 2009).

Durante dez anos, mais intensamente no período de 1989 a 1993, equipes do JBRJ realizaram coletas de dados e de materiais em diversas áreas da REMC para estudos em diferentes linhas de pesquisas (Lima \& Guedes-Bruni 1997). Para o estudo fitossociológico foram realizadas coletas em duas áreas definidas nas quais foram coletadas amostras de todos os espécimes lenhosos com DAP (diâmetro a altura do peito) igual ou superior a $2,5 \mathrm{~cm}$, assim como materiais férteis em caminhadas livres. O acervo de espécimes coletados encontra-se depositado no herbário do Instituto de Pesquisas Jardim Botânico do Rio de Janeiro (RB), com duplicatas distribuídas a outras instituições do Brasil e do exterior. As pesquisas realizadas integravam-se a um programa amplo do Conselho Nacional de Desenvolvimento Científico e Tecnológico (CNPq), implementado em 1987 - Linhas de Ação em Botânica, que tinha entre os seus objetivos promover o levantamento em áreas detectadas como prioritárias cuja vegetação encontrava-se ameaçada. Nessas áreas, havia a necessidade de estudos botânicos, com vistas ao seu aproveitamento racional, propiciando o melhoramento socioeconômico e a conservação, bem como estimular a formação de recursos humanos (Nogueira 1987). Parte dos estudos realizados são apresentados em três livros: Reserva Ecológica de Macaé de Cima, Nova Friburgo, RJ: Aspectos Florísticos das espécies vasculares (vol 1. Lima \& Guedes-Bruni 1994; vol 2. Lima \& GuedesBruni 1996) e Serra de Macaé de Cima: Diversidade Florística e Conservação em Mata Atlântica (Lima \& Guedes-Bruni 1997).

Os inventários florísticos e fitossociológicos realizados na REMC resultaram na identificação de 883 angiospermas, das quais 17 eram novas para a ciência (Lima \& Guedes-Bruni 1997). As observações realizadas em campo e os espécimes depositados em coleções permitiram o desenvolvimento de monografias para diversas famílias de plantas vasculares (26 famílias no vol. 1; 32 famílias no vol. 2) publicadas predominantemente em Lima \& Guedes-Bruni (1994 e 1996), mas também em revistas científicas (Baumgratz \& Souza 2011; Quinet \& Andreata 2002, entre outros).

Informações sobre riqueza, abundância e distribuição geográfica das espécies são particularmente críticas para a conservação dos ecossistemas, constituindo a base para a delimitação de áreas prioritárias para a conservação (Bini et al. 2006; Joly et al. 2014, Luber et al. 2016). Aliados a estudos de monitoramento da flora, representam uma estratégia adequada no entendimento de como as florestas tropicais mantem sua alta diversidade, e como elas são afetadas por padrões climáticos globais (Picard et al. 2010).

A família Myrtaceae foi monografada no primeiro volume da Flora da REMC (Barroso \& Peron 1994). Este estudo representou um avanço no conhecimento não só sobre as Myrtaceae do Rio de Janeiro, mas para as Myrtaceae do Brasil, pois muitas espécies apresentadas na Flora Brasiliensis (Berg 1857-1859) eram conhecidas apenas pela coleta tipo, consideradas raras ou até mesmo extintas como Eugenia ellipsoidea Kiaersk. e Myrcia coelosepala Kiaersk. (Barroso \& Peron 1994). A família destacou-se entre as mais importantes com 47 espécies, distribuídas entre 11 gêneros, sendo Myrcia e Eugenia os mais representativos. No estudo fitossociológico destacou-se como a família de maior riqueza e valor de importância(VI) (Guedes-Bruni \& Pessoa 1997; Pessoa et al. 1997). O gênero Psidium foi representado por 3 espécies: Psidium guineense Sw., Psidium robustum O.Berg e Psidium spathulatum Mattos.

As coleções de Macaé de Cima ainda eram pouco representativas nos herbários, e as identificações eram baseadas, a maior parte das vezes, na descrição original da espécie e na análise de fotografias de tipos impressas em papel, enviadas de herbários do exterior, com pouca riqueza de detalhes. Após duas décadas, as possibilidades de se visualizar coleções tipos em fotografias digitais, com alta resolução, aliado a maior riqueza das coleções em exemplares oriundos da APA Estadual de Macaé de Cima, é apresentada uma nova abordagem para o gênero Psidium. São assinaladas seis espécies para a APA de Macaé de Cima, representando $46 \%$ do total de espécies do gênero presentes no estado do Rio de Janeiro, sendo uma delas nova ocorrência para o estado. Das espécies citadas por Barroso \& Peron (1994) $P$. guineense foi confirmada, e as duas outras tiveram a identificação taxonômica atualizada. O estudo demonstra a importância de revisitar trechos de florestas com alta riqueza e diversidade, ainda que anteriormente explorados cientificamente, coletar espécimes buscando complementar informações, permitindo maior conhecimento dos ambientes onde ocorrem de modo a fornecer maiores subsídios à conservação de espécies e gestão de áreas protegidas. 


\section{Material e Métodos}

A APA Estadual de Macaé de Cima está situada nas encostas da Serra do Mar, com área na porção sul do município de Nova Friburgo e na porção norte de Casimiro de Abreu ( $22^{\circ} 17^{\prime} 52^{\prime \prime}$ e $22^{\circ} 27^{\prime} 08^{\prime \prime} \mathrm{S}$; $42^{\circ} 34^{\prime} 43^{\prime \prime}$ e $42^{\circ} 12^{\prime} 16^{\prime \prime} \mathrm{W}$; Inea 2014; Fig. 1). A Reserva Ecológica de Macaé de Cima foi instituída por um decreto municipal $\left(\mathrm{n}^{\circ}\right.$ 156, de 3 de janeiro de 1990), por sua importância biológica e social demonstrada em diferentes estudos até então realizados. Englobava uma área de 7.000 hectares de florestas bem conservadas e com baixa densidade populacional (Sá Rego 2009). Atualmente a área é preservada como Área de Proteção Ambiental Estadual (Decreto Estadual ${ }^{\circ}$ 29.213, de 14 de setembro de 2001), abrange 35.037 hectares e engloba as nascentes dos rios Macaé de Cima, Rio Bonito, Rio das Flores, Rio Santo Antônio e seus afluentes (Inea 2014). Descrição da vegetação local, bem como dos estudos realizados pelo Programa Mata Atlântica do JBRJ encontra-se em Lima e Guedes-Bruni (1997).
Foram analisados os espécimes citados na Flora da Reserva Ecológica de Macaé de Cima, além de coletas posteriores feitas na área e depositadas nos herbários RB, R, UB, SPF e VIES. Expedições a campo na APA Estadual de Macaé de Cima foram realizadas nos meses de julho e setembro de 2015 para coleta de novas amostras, observação e fotografia dos espécimes em campo. As técnicas de coleta e preparo do material seguiram Peixoto \& Maia (2013) e o material foi depositado no herbário RB. Material adicional de outras localidades foi citado quando não se tinha material completo para descrição. A terminologia morfológica utilizada seguiu Hickey \& King (2000) e Radford et al. (1974). A APA Estadual de Macaé de Cima, em exemplares herborizados, encontra-se citado de diferentes maneiras: Alto Macaé, Alto Macaé de Nova Friburgo, Reserva Ecológica de Macaé de Cima e APA de Macaé de Cima. No material examinado optou-se por utilizar a denominação Macaé de Cima.

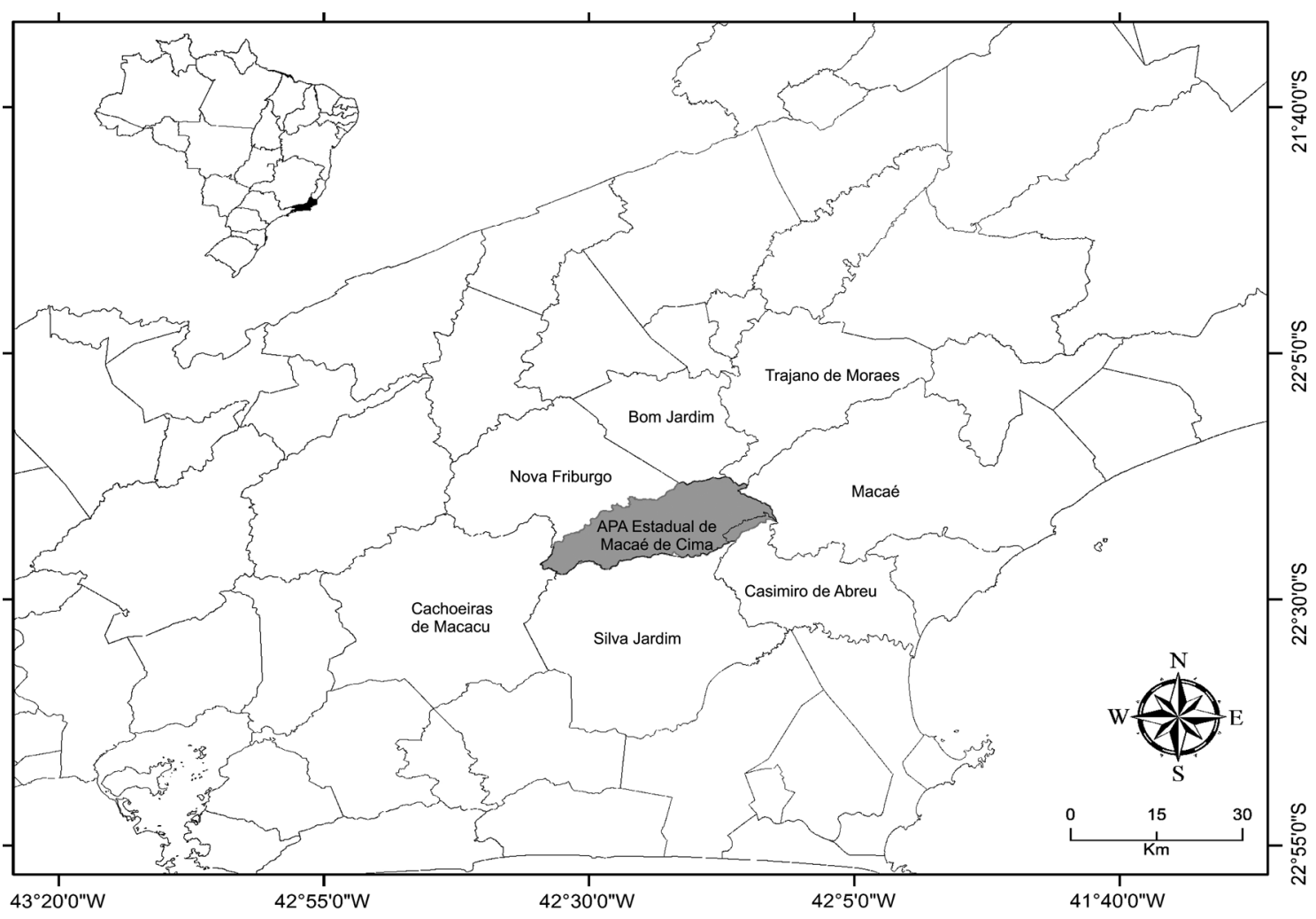

Figura 1 - Localização da Área de Proteção Ambiental Estadual de Macaé de Cima no Estado do Rio de Janeiro. Figure 1 - Localization of Macaé de Cima Environmental Protection Area in the state of Rio de Janeiro. 


\section{Resultados}

1. Psidium L., Sp. Pl. 1: 470. 1753.

Árvores ou arbustos, ramos glabros ou pilosos, cilíndricos ou quadrangulares. Folhas pecioladas, com pontoações translúcidas, glabras a pilosas, margem inteira; nervação broquidródroma. Inflorescência axilar ou terminal, auxotélica, em dicásio, racemo, ou flores solitárias. Botão floral piriforme ou com constrição acima do ovário, cálice com lobos inteiramente fusionados ou parcialmente fusionados; quando fusionados o ápice pode ser arredondado ou apiculado, rasgando-se na antese em 4-5 lobos calicinos irregulares; corola 4(-5)mera, alva; filetes livres, anteras rimosas, dorsifixas; estigma capitado ou punctiforme, ovário 2-5 locular, óvulos 2-90 por lóculo. Fruto globoso, elíptico, piriforme ou oblongo com cálice persistente; sementes 4-325, testa óssea com várias camadas de células sobrepostas, embrião com hipocótilo longo e cotilédones pequenos a rudimentares.

\section{Chave de identificação das espécies de Psidium ocorrentes na APA Estadual de Macaé de Cima}

1. Plantas com indumento ferrugíneo

2. Botão floral constrito acima do ovário, cálice com lobos inteiramente fusionados

1.2. Psidium guineense

2'. Botão floral não constrito acima do ovário, cálice parcialmente fusionado ... 1.6. Psidium rufum

1'. Plantas glabras ou glabrescentes, indumento não ferrugíneo ......................................................... 3

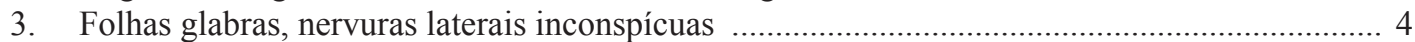

3'. Folhas glabrescentes, nervuras laterais evidentes em ambas as faces ..................................... 5

4. Arbórea ou arbustiva 1-3 $\mathrm{m}$ alt., pecíolo 5-8 mm compr. .............1.1. Psidium cattleianum 4'. Arbórea 6-14m alt., pecíolo 10-30 mm compr. ......................1.3. Psidium longipetiolatum

5. Arbórea ca. $8 \mathrm{~m}$ alt., pecíolos 3-8 mm compr., frutos 9-13 × 6-12 mm

1.4. Psidium myrtoides

5'. Arbustiva ca. $3 \mathrm{~m}$ alt., pecíolos 1-2mm compr., frutos $4-5 \times 4,5-5 \mathrm{~mm}$

1.5. Psidium ovale

1.1. Psidium cattleianum Sabine, Trans. Hort. Soc. London 4: 317, 1821.

Ilustração em Landrum \& Kawasaki 1997.

Árvores ou arbustos 1-3 m alt.; ramos glabros ou glabrescentes, cilíndricos, $0,5-6 \mathrm{~mm}$ diâm. Pecíolos 5-8 × 0,5-2,5 mm, canaliculados. Folhas obovadas, 3,2-6,5 × 1,3-4 cm, ápice obtuso ou apiculado, base cuneada, margem levemente revoluta, cartáceas ou coriáceas, glabras em ambas as faces; pontoações inconspícuas em ambas as faces; nervura central sulcada na face adaxial, saliente na face abaxial, nervuras laterais 6-12 pares, inconspícuas na face adaxial, salientes na face abaxial, nervuras intramarginais afastadas da margem 1-3 mm. Flores solitárias, brácteas ovadas, $1-5 \times 1-2,5 \mathrm{~mm}$, pedicelos 3-18 × 0,5-2 $\mathrm{mm}$, bractéolas ovadas ou deltóides, $2 \times 0,8-1$ $\mathrm{mm}$, persistentes. Botões florais 5-12 × 3,5-6 mm, cálice com lobos parcialmente fusionados, 4(-5)mero, lobos 2-8 $\times 2-10 \mathrm{~mm}$; corola 5-mera, pétalas 5-8 $\times 4-5 \mathrm{~mm}$; filetes $5-10 \mathrm{~mm}$ compr., anteras 0,5-1 × 0,5-1 mm; ovário 4-locular, óvulos (12)13 por lóculo, estiletes 5-8 $\mathrm{mm}$ compr., estigma captado. Frutos globosos, 15-40 × 9-25 mm, glabros, sementes 38-45, angulosas, 5-6 × $3-5 \mathrm{~mm}$.
Espécie comum em vegetação de restinga ocorrendo em quase todos os estados litorâneos brasileiros (BFG 2015). O binômio Psidium cattleianum não foi utilizado por Barroso \& Peron (1994) na Flora de Macaé de Cima. O espécime C.M.Vieira 456 foi identificado como $P$. spathulatum, hoje sinônimo de $P$. ovale (SoaresSilva \& Proença 2006). De fato, as duas espécies se assemelham quanto ao formato das folhas, o que provavelmente levou a identificação equivocada, sendo diferenciadas pela dimensão das folhas e frutos, maiores em P. cattleianum. Em Macaé de Cima foi encontrada no sub-bosque da Floresta. Flores coletadas em dezembro e frutos em março. Material examinado: Nova Friburgo, Macáe de Cima, 12.II.1872, fl., A. Glaziou 6887 (P); Nova Friburgo, Reserva Ecológica Municipal de Macaé de Cima, estrada para a fazenda Ouro Verde, $22^{\circ} 33^{\prime} / 22^{\circ} 28^{\prime}$ 'S, $42^{\circ} 30^{\prime} / 42^{\circ} 34^{\prime} \mathrm{W}$, fl., C.M.Vieira 456 (RB); Reserva Ecológica Municipal de Macaé de Cima, margens do Rio Macaé, próximo ao H.F.S Joao, $22^{\circ} 33^{\prime} / 22^{\circ} 28^{\prime}$ 'S, $42^{\circ} 30^{\prime} / 42^{\circ} 34^{\prime} \mathrm{W}, 12 . I X .1993$, fr., F.C.P. Garcia 750 (RB, UB, K); Rio Bonito de Lumiar, Pousada dos Cristais 1.III.2004, fr., E.J.Lucas et al. 220 (RB, K); Sítio dos Lírios Brancos, 17.II.2001, fr., A.Quinet 1973 (RB, 
RFA); estrada para Macaé de Cima, Km 8, 6.III.1986, fr, H.C. Lima et al. 2673 (RB).

1.2. Psidium guineense Sw. Prodr. Veg. Ind. Occ.: 77 (1788).

Fig. 2a

Ilustração em Landrum \& Kawasaki 1997.

Arbustos $1 \mathrm{~m}$ alt.; ramos jovens com indumento ferrugíneo, quadrangulares $1-3 \mathrm{~mm}$ diâm. Pecíolos 3-10 × 0,5-2 mm, canaliculados. Folhas elípticas ou ovadas, 5-12 × 2-6 cm, ápice agudo ou obtuso, base aguda ou obtusa, margem levemente revoluta, cartáceas a coriáceas, pilosas na face abaxial, pubérulas na face adaxial; pontoações evidentes em ambas as faces; nervura central sulcada na face adaxial, saliente na face abaxial, nervuras laterais 7-9 pares, sulcadas na face adaxial, salientes na face abaxial, nervuras intramarginais afastadas da margem 0,5-2 mm. Flores em dicásio trifloro ou solitárias, brácteas ovadas ou lineares, $1-3 \times 0,5-1 \mathrm{~mm}$, pedicelos 2-17 $\times 0,3-2 \mathrm{~mm}$, bractéolas ovadas ou lineares, 1,5-3 × 0,4-1 mm. Botões florais piriformes, 6-14 $\times$ 4-6 mm, constritos imediatamente acima do ovário, cálice com lobos inteiramente fusionados rasgando-se na antese em lobos irregulares, 4(-5)-mero, lobos calicinos, 4-8 $\times 2-8 \mathrm{~mm}$; corola 5-mera, pétalas 7-13 $\times 4-11 \mathrm{~mm}$, filetes 7-12 mm compr., anteras rimosas, $1-2 \times 0,3-0,8 \mathrm{~mm}$; ovários 4-5 locular, óvulos (70-)77 por lóculo, estilete 5-8 $\mathrm{mm}$ compr., estigma capitado. Frutos globosos, 10-25 × 8-22 mm, pilosos ou glabrescentes, sementes 223-240, angulosas 2-2,5 × 1,5-2 mm.

A espécie ocorre desde a América Central até o Sul do Brasil (Brandão et al. 2002). No Brasil tem ocorrência assinalada em quase todos os estados nos domínios da Floresta Amazônica, Caatinga, Cerrado e Floresta Atlântica (BFG 2015). Em Macaé de Cima foi encontrada nas bordas da mata ou em áreas antropizadas. Flores coletadas em outubro e frutos em março.

Material examinado: Nova Friburgo, Macaé de Cima, Fazenda Ouro Verde, trilha para a bacia, 15.VIII.1993, C.M.Vieira \& L.C.Gurken 347 (RB); Reserva Ecológica Municipal de Macaé de Cima. estrada para a fazenda Ouro Verde, 27.VIII.1993, fr, C.M. Vieira et al. 387 (RB); Área de Proteção Ambiental Macaé de Cima, 17.X.2009, fl, R.Brum-Castro et al. 06 (RFFP, RB).

1.3. Psidium longipetiolatum D.Legrand Sellowia, 13: 341, 1961. Fig. 2b

Ilustração em Legrand \& Klein 1977.

Árvores 6-14 m alt.; ramos glabros ou glabrescentes, cilíndricos, 1,5-6 mm diâm. Pecíolos 10-30 × 1-1,5 mm, canaliculados.
Folhas obovadas, raro elípticas, 6-12 × 2,3-5,5 $\mathrm{cm}$, ápice acuminado, agudo ou obtuso, base cuneada ou obtusa, margem revoluta, cartáceas, glabras; pontoações inconspícuas em ambas as faces; nervura central sulcada na face adaxial, saliente na face abaxial, nervuras laterais 8-10 pares, inconspícuas na face adaxial, evidentes na face abaxial, nervuras intramarginais afastadas da margem 1-3 mm. Flores solitárias ou racemos, 2-4 flores, brácteas ovadas, 2-2,5 × 2,5-3 mm, pedicelos 7-30 × 0,7-1 mm, bractéolas ovadas ou deltoides, 0,2-0,3 × 0,4-0,5 mm. Botões florais piriformes, $13-15 \mathrm{~mm}$; cálice com lobos inteiramente fusionados rasgando-se na antese em lobos irregulares, 5-mero, lobos calicinos 2-3 $\times$ 3-5 mm; flores não vistas; ovário $4(-5)$-locular, óvulos 8-10 por lóculo. Frutos globosos, 13-20 $\times 10-17 \mathrm{~mm}$, glabros, sementes 11-14, angulosas, 4-6 × 4-5 mm.

Espécie restrita a Floresta Atlântica nos estados do Sudeste e Sul do Brasil (BFG 2015). $\mathrm{O}$ binômio Psidium longipetiolatum não foi utilizado por Barroso \& Péron (1994). O espécime C.M.Vieira 460 foi identificado por estes autores como Psidium robustum. De fato, as espécies se assemelham quanto ao hábito arbóreo e formato obovado das folhas, mas se diferenciam principalmente pelo longo comprimento do pecíolo (10-30 mm), caractere diagnóstico de Psidium longipetiolatum. Flores coletadas em novembro e frutos em janeiro.

Material examinado: Nova Friburgo, Macaé de Cima, 1994, fl., C.M.Vieira 460 et al. (RB); Macaé de Cima, Sítio do Cedro. Área de Proteção Ambiental de Macaé de Cima, 22²1'1'S, 42 26'25'W, Elev. 865 m, 3.XI.2013, fl., P. Pietro (RB 595055); Macaé de Cima, Sítio do

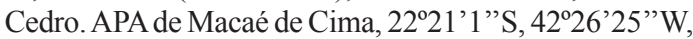
Elev. 865 m, 26.I.2014, fr., P. Pietro (RB 595299).

1.4. Psidium myrtoides O.Berg, Fl. bras.14 (1): 384, 1857.

Fig. 2c

Árvores $8 \mathrm{~m}$ alt.; ramos jovens glabros ou glabrescentes, cilíndricos, 1,5-2 mm diâm. Pecíolos 3-8 × 0,5-1,5 mm, sulcados. Folhas obovadas, elípticas ou ovadas $5-13 \times 2-4,5 \mathrm{~cm}$, ápice acuminado, agudo ou obtuso, base cuneada ou aguda, margem levemente revoluta, cartáceas a coriáceas, discolores, esparsamente pubescentes ao longo das nervuras e bordo foliar; pontoações evidentes em ambas as faces; nervura central sulcada na face adaxial, saliente na face abaxial, nervuras laterais $10-17$ pares, evidentes em ambas as faces, nervuras intramarginais afastadas da margem 1-2 mm. Inflorescência em racemos ou 


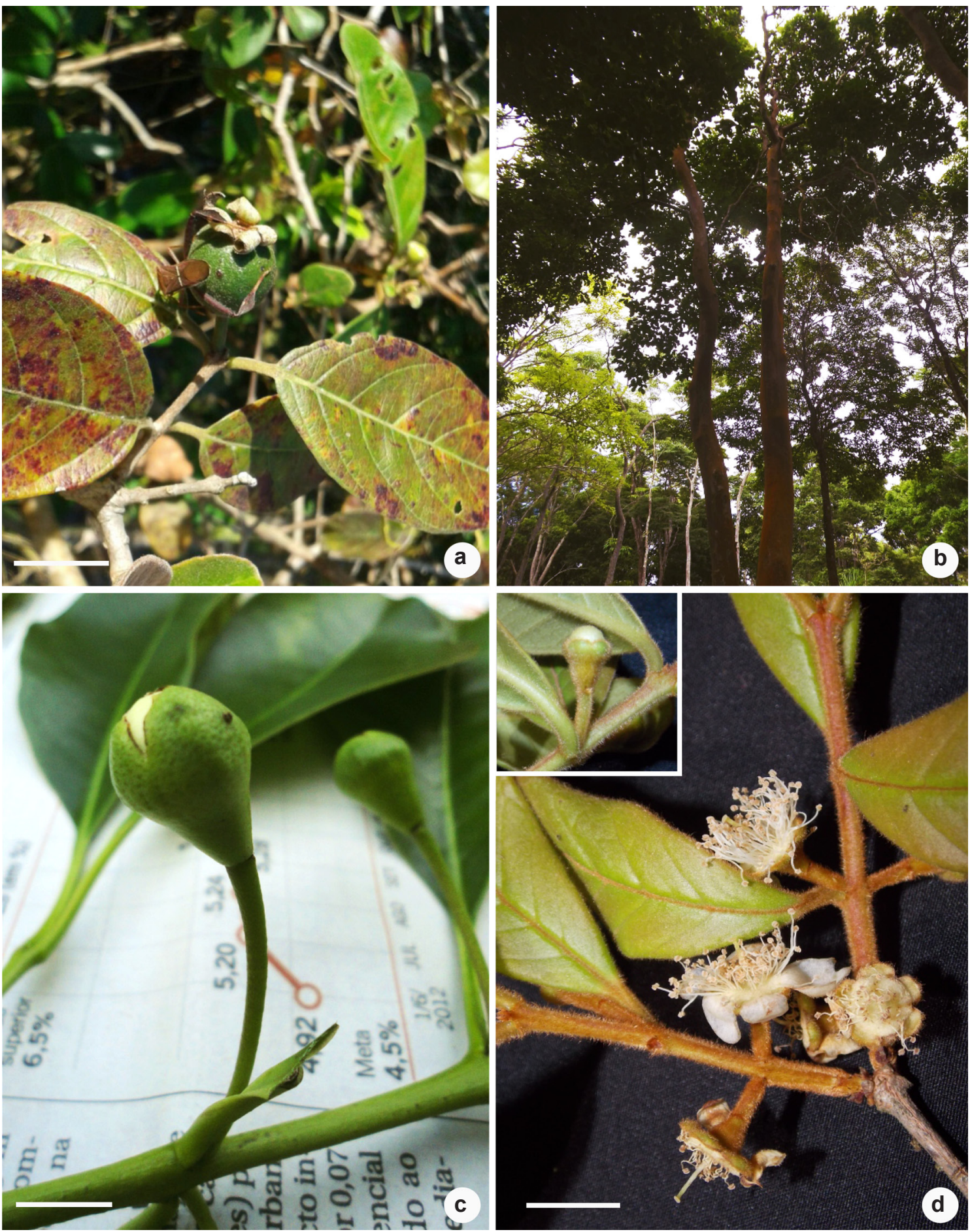

Figura 2 - a. Psidium guineense - detalhe do fruto; b. P. longipetiolatum - hábito arbóreo; c. P. longipetiolatum - detalhe da antese; d. $P$. rufum - ramo com flores e detalhe do botão floral com cálice parcialmente fusionado. Barras de escala $=5 \mathrm{~mm}$. Fotos: a,b,d. Amélia Tuler; c. Pablo Pietro Viany.

Figure 2 - a. Psidium guineense-detail of the immature fruit; b. P. longipetiolatum-arboreal habit; c. P. longipetiolatum-floral buds in anthesis; $\mathrm{d}$. P. rufum - branch with flowers and detail of floral bud with calyx partially fused. Scale bars $=5 \mathrm{~mm}$. Fotos: a,b,d. Amélia Tuler; c. Pablo Pietro Viany . 
inflorescência auxotélica, 2-8 flores, brácteas ovadas ou deltóides, $2-3 \times 1,5-2 \mathrm{~mm}$, pedicelos $5-12 \times 0,2-1 \mathrm{~mm}$, bractéolas ovadas ou lineares, $0,5-1 \times 0,2-1 \mathrm{~mm}$. Botões florais piriformes, 2-5 × 2-3,5 mm; cálice com lobos parcialmente fusionados na antese, 5-mero, lobos calicinos 1,5-3 $\times 1,5-2 \mathrm{~mm}$, arredondados; corola 5-mera, pétalas 4-5 × 3-5 mm, alvas; filetes 3-5 mm compr., anteras, 0,5-1 × 0,5-1 mm; ovário 4-locular, óvulos 4(-6) por lóculo, estilete $5 \mathrm{~mm}$ compr., estigma punctiforme. Frutos piriformes ou globosos, 9-13 $\times$ 6-12 mm, glabros; sementes 5-8, angulosas, 4-5 × 2-3 mm.

Espécie de ampla distribuição, ocorrendo nos estados de TO, BA, CE, MA, DF, GO, ES, MG, RJ, SP, PR e RS nos domínios da Caatinga, Cerrado e Floresta Atlântica (BFG 2015). Em Macaé de Cima, a espécie foi encontrada próxima à margem do rio Macaé, em altitude de ca. de $750 \mathrm{~m}$. Frutos coletados em março.

Material examinado: Nova Friburgo, Macaé de Cima, 1.III.2004, fr., E.J.Lucas et al. 224 (RB, K).

Material adicional: BRASIL. RIO DE JANEIRO: São José do Vale do Rio Preto, 13.IX.2000, fl., F.M.B Pereira 48 (RFA, RB).

1.5. Psidium ovale (Spreng.) Burret, Notizbl. Bot. Gart. Berlin-Dahlem 15: 485,1941.

Ilustração em Soares-Silva \& Proença 2006.

Arbustos $3 \mathrm{~m}$ alt.; ramos glabrescentes, ramos achatados quando jovens, 0,5-3 mm diâm. Pecíolos 1-2 × 0,5-1 mm, canaliculados. Folhas ovadas raro elípticas $1-3,5 \times 0,5-2 \mathrm{~cm}$, ápice obtuso ou arredondado, base aguda ou curtamente atenuada, margem revoluta, ciliada quando jovem, cartáceas; pontoações salientes em ambas as faces; nervura central sulcada ou plana na face adaxial, salientes na face abaxial, nervuras laterais 6-10 pares, evidentes em ambas as faces, nervuras intramarginais afastadas da margem 0,5-1 $\mathrm{mm}$. Flores solitárias, em racemos ou em inflorescências auxotélicas, 2-4 flores, brácteas deltóides, ovadas ou estreito-ovadas $0,5-1,5 \times 0,3-1 \mathrm{~mm}$, ciliadas, pedicelos 2-6 mm compr.; bractéolas deltóides, ovadas ou lineares $0,4-1 \times 0,2-0,5 \mathrm{~mm}$, tricomas ao longo do bordo; botões florais piriformes, cálice com lobos parcialmente fusionados, 1,5-3 $\times 1-2 \mathrm{~mm}, 5$-mero, lobos calicinos $0,2-1 \times 1-1,5$ $\mathrm{mm}$, arredondados, bordo ciliado; corola 4-mera, pétalas $2,5-3 \times 1,5-2 \mathrm{~mm}$, filetes $1,5-2 \mathrm{~mm}$ compr., anteras rimosas $0,3-0,5 \times 0,2-0,5 \mathrm{~mm}$; ovário 2-3 locular, óvulos (2-)4 por lóculo, estilete $2 \mathrm{~mm}$ compr., estigma punctiforme. Frutos globosos 4-5 × 4,5-5 mm, glabros; sementes 4, arredondadas, 4-5 × 2,5-3 $\mathrm{mm}$.

Espécie restrita a Floresta Atlântica, com ocorrência assinalada nos estados do PR e SC, na Região Sul e nos estados do ES, MG e SP na Região Sudeste (BFG 2015), sendo sua ocorrência aqui estendida ao estado do Rio de Janeiro. SoaresSilva e Proença (2006) afirmam que a combinação Psidium ovale (Spreng.) Burret baseada em uma das primeiras espécies brasileiras de Psidium, descrita como Myrtus ovalis Spreng, foi ignorada nas identificações de herbários e floras, sendo a espécie descrita sob diferentes sinônimos (Myrcianthes brunnea var. grandifolia O.Berg, P. spathulatum Mattos, $P$. hatschbachii D.Legrand, $P$. imaruinense Mattos, $P$. hagelundianum Mattos). De fato, nas coleções por nós estudadas encontramos a espécie identificada sob diferentes nomes. Além de Nova Friburgo, foram identificados espécimes nos municípios de Santa Maria Madalena, na Pedra Dubois, Itatiaia, Parque Nacional do Itatiaia e Teresópolis, na Serra dos Órgãos, em altitudes de 1000-1500 m. Em Macaé de Cima foi coletada próximo às margens do Rio Macaé. Flores coletadas em fevereiro e frutos coletados em setembro.

Material examinado: Nova Friburgo, Macaé de Cima, 10.IX.1994, C.M.Vieira \& L.C.Gurken 640 (RB).

Material adicional: BRASIL. RIO DE JANEIRO: Itatiaia, Parque Nacional do Itatiaia $22^{\circ} 15^{\prime}-22^{\circ} 28^{\prime} \mathrm{S}$, 44⒊'-444' 'W, Visconde de Mauá, Cruz, antiga Fazenda da Cruz, margem do Rio Cruz, Alt. 1.350 m.s.m, 6.X.1994, fr., S.J. Silva Neto 515 (RB). Santa Maria Madalena, Pedra Dubois, 22.II.1983, fl., H.C.Lima \& T. Plowman 1869 (RB).

1.6. Psidium rufum Mart. ex DC., Prodr. 3: 234, 1828.

Ilustração em Kawasaki 1989.

Fig. 2d

Árvores 2-3 m alt.; ramos com indumento ferrugíneo, cilíndricos, com nós bem marcados, 1-3 mm diâm. Pecíolos 4-5 × 0,8-1 mm, canaliculados. Folhas elípticas a estreitamente elípticas, 5-10 $\times$ 2-3 cm, ápice obtuso ou acuminado, base cuneada a obtusa, margem levemente revoluta, pubérulas a glabras na face adaxial, pubescentes a pubérulas na face abaxial, cartáceas a coriáceas; pontoações evidentes em ambas as faces; nervura central sulcada na face adaxial, saliente na face abaxial, nervuras laterais 8-12 pares, sulcadas na face adaxial, muito evidentes na face abaxial, dando aspecto bulado ao limbo; nervuras intramarginais afastadas da margem 1-1,5 mm. Flores solitárias ou racemos, 2-8 flores; brácteas deltóides, ovadas 
ou estreito ovadas $1,5-2 \times 1-2 \mathrm{~mm}$, tricomas ferrugíneos ao longo do bordo, pedicelos 3-5 mm compr., bractéolas não vistas. Botões florais piriformes, 5-8 × 1-2 mm; cálice com lobos parcialmente fusionados, 5-mero, lobos calicinos $1-2 \times 1,5-2 \mathrm{~mm}$; corola 5-mera, pétalas 4-5 × 2-3 $\mathrm{mm}$, alvas; filetes 1,5-2 mm compr., anteras $0,8-1$ $\times$ 0,5-1 mm; ovário 2-3 locular, óvulos (2-)5 por lóculo, estilete 3-5 mm compr., estigma captado. Frutos globosos, 2-4 × 2-3 mm, pubérulos a glabros; sementes 8-10, angulosas, 3-4 × 2-3mm.

Espécie de ampla distribuição, ocorrendo nos estados de BA, CE, DF, GO, ES, MG, RJ, SP e PR nos domínios do Cerrado e da Mata Atlântica (BFG 2015) Em Macaé de Cima, indivíduos da espécie foram encontrada em áreas de encosta de morros, no interior de florestas, em bordas ou próximos à áreas antropizadas, como estradas e pastagens. Flores coletadas de setembro a janeiro e frutos coletados em novembro.

Material examinado: Nova Friburgo, Macaé de Cima, 5.XI.1881, fl., A. Glaziou 13446 (P); 27.XI.1888, fl., A. Glaziou 17683 (P); Distrito de Lumiar, sítio do Cedro, 15.XII.2011, fl., R.Borges et al. 1198 (RB); proximidades do Sítio do Cedro, Macaé de Cima, 19.IX.2015, fl., A.C.Tuler et al. 536 (RB); proximidades do Sítio do Cedro, Macaé de Cima, 19.IX.2015, fl., A.C.Tuler et al. $538(\mathrm{RB})$.

\section{Agradecimentos}

Agradecemos à CAPES, a concessão da bolsa de Doutorado ao primeiro autor; ao CNPq, a bolsa de Produtividade ao segundo autor; e aos curadores dos herbários visitados. Também agradecemos a Elton John Lírio, Pablo Viany Pietro e Fernanda Masullo, a companhia em campo.

\section{Referências}

Barroso GM \& Peron M (1994) Myrtaceae In: Lima MPM \& Guedes-Bruni RR (orgs.) Reserva Ecológica de Macaé de Cima, Nova Friburgo, RJ: aspectos florísticos das espécies vasculares. Jardim Botânico do Rio de Janeiro, Rio de Janeiro. Pp. 261-296.

Baumgratz JFA \& Souza MLDR (2011) Melastomataceae na Reserva Ecológica de Macaé de Cima, Nova Friburgo, Rio de Janeiro, Brasil. II - Leandra (Miconieae). Rodriguésia 62: 629-662.

Berg O (1857-1859) Myrtaceae. In: Martius CPF (ed.) Flora brasiliensis. R Oldenbourg, Munich, Leipzig. Vol. 14, pars 1, pp. 1-656.

Bini LM, Diniz-Filho JAF, Rangel TFLVB, Bastos RP \& Pinto MP (2006) Challenging Wallacean and Linnean shortfalls: knowledge gradients and conservation planning in a biodiversity hotspot. Diversity and Distributions 12: 475-482. DOI: 10.1111/j.1366-9516.2006.00286.x

BFG - The Brazil Flora Group (2015) Growing knowledge: an overview of seed plant diversity in Brazil. Rodriguésia 66: 1085-1113.

Brandão M, Laca-Buendia JP \& Macedo JF (2002) Árvores nativas e exóticas do estado de Minas Gerais. EPAMIG, Belo Horizonte. 528p.

Guedes-Bruni RR \& Pessoa SVA (1997) Florística e fitossociologia do componente arbustivo-arbóreo de um trecho preservado de Floresta Montana na Reserva Ecológica de Macaé de Cima. In: Lima HC de; Guedes-Bruni RR (org.) Serra de Macaé de Cima: diversidade florística e conservação em Mata Atlântica. Jardim Botânico do Rio de Janeiro, Rio de Janeiro. Pp. 127-146.

Hickey M \& King C (2000) The Cambridge illustrated glossary of botanical terms. Cambridge University Press, Cambridge. 208p.

Inea - Instituto Estadual do Ambiente (2014) APA Estadual de Macaé de Cima: Plano de manejo - informações sintetizadas da UC. Disponível em <http://www.inea.rj.gov.br/cs/groups/public/ documents/document/zwew/mdgz/ edisp/ inea0083754.pdf $>$. Acesso em 15 maio 2016.

Joly CA, Metzger JP \& Tabarelli M (2014) Experiences from the Brazilian Atlantic Forest: ecological findings and conservation initiatives. New Phytologist 204: 459-473.

Kawasaki ML (1989) Flora da Serra do Cipó, Minas Gerais: Myrtaceae. Boletim de Botânica da Universidade de São Paulo 11: 121-170.

Landrum LR \& Kawasaki ML (1997) The genera of Myrtaceae in Brazil: an illustrated synoptic treatment and identification keys. Brittonia 49: 508-536.

Legrand D \& Klein RM (1977) Myrtaceae. In: Reitz R (ed.) Flora ilustrada catarinense. Herbário Barbosa Rodrigues, Itajaí. Pp. 1-876.

Lima HC \& Guedes-Bruni RR (1997) Serra de Macaé de Cima: diversidade florística e conservação em Mata Atlântica. Jardim Botânico do Rio de Janeiro, Rio de Janeiro. 346p.

Lima MPM \& Guedes-Bruni RR (orgs.) (1994) Reserva ecológica de Macaé de Cima, Nova Friburgo, RJ: aspectos florísticos das espécies vasculares.Vol. 1. Jardim Botânico do Rio de Janeiro, Rio de Janeiro. 404p.

Lima MPM \& Guedes-Bruni RR (orgs.) (1996) Reserva ecológica de Macaé de Cima, Nova Friburgo, RJ: aspectos florísticos das espécies vasculares.Vol. 2. Jardim Botânico do Rio de Janeiro, Rio de Janeiro. $465 \mathrm{p}$.

Luber J, Tuler AC, Torres F, Christ JA, GuidoniMartins KG, Zanetti M, Hollunder RK, Manhães VC, Zorzanelli JPF, Mendonça ES, Garbin ML \& 
Carrijo TT (2016) List of angiosperm species in an Atlantic Forest fragment reveals collection gaps in Espírito Santo state, Brazil. Check List 12: 1835. DOI: $10.15560 / 12.1 .1835$

Mittermeier RA, Gil PR, Hoffmann M, Pilgrim J, Brooks T, Mittermeier CG, Lamourex J \& Fonseca GAB (2004) Hotspots revisited. CEMEX, Mexico City, $392 \mathrm{p}$.

Nogueira E (1987) Botânica no Brasil - Descrição do quadro atual/ Linhas de Ação. Ministério de Ciência e Tecnologia, CNPq, Brasília. 54p.

Pessoa SVA, Guedes-Bruni RR \& Kurtz BC (1997) Composição florística e estrutura do componente arbustivo-arbóreo de um trecho secundário de Floresta Montana na Resrva Ecológica de Macaé de Cima. In: Lima HC de \& Guedes-Bruni RR (org.) Serra de Macaé de Cima: diversidade florística e conservação em Mata Atlântica. Jardim Botânico do Rio de Janeiro, Rio de Janeiro. Pp. 147-168.

Picard N, Magnussen S, Banak LN, Namkosserena S \& Yalibanda Y (2010) Permanent sample plots for natural tropical forests: a rationale with special emphasis on Central Africa. Environmental Monitoring and Assessment 164: 279-295.

Quinet A \& Andreata RHP (2002) Lauraceae Jussieu na Reserva Ecológica de Macaé de Cima, Município de Nova Friburgo, Rio de Janeiro, Brasil. Rodriguésia 53: 59-121.

Radford AE, Dickinson WC, Massey JR \& Bell CR (1974) Vascular plant systematics. Harper \& Row, New York. 891p.

Ribeiro MC, Metzger JP, Martensen AC, Ponzoni FJ \& Hirota MM (2009) The Brazilian Atlantic Forest: how much is left, and how is the remaining forest distributed? Implications for conservation. Biological Conservation 142: 1141-1153.

Sá Rego VVB (2009) Conselhos gestores de Áreas de Proteção Ambiental: instrumento de autonomia ou de controle? In: Sá Rego VVB. Anais do XIV Congresso Brasileiro de Sociologia. Rio de Janeiro, Rio de Janeiro. Pp. 1-20.

Soares-Silva LH \& Proença CE (2006) An old species revisited and a new combination proposed in Psidium (Myrtaceae). Kew Bulletin 61: 199-204. 